\title{
The concepts of area and perimeter: Insights and misconceptions of Grade 10 learners
}

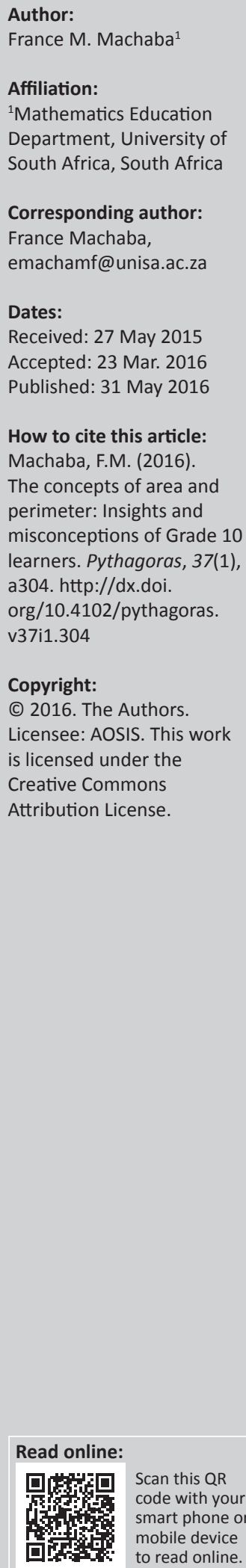

This article focuses on learners' understanding and their descriptions of the concepts of area and perimeter, how learners solve problems involving area and perimeter and the relationship between them and misconceptions, and the causes of these misconceptions as revealed by learners when solving these problems. A written test was administered to 30 learners and clinical interviews were conducted with three of these learners, selected based on their responses in the test. This article shows that learners lack a conceptual understanding of area and they do not know what a perimeter is. Learners also hold misconceptions about the relationship between area and perimeter. It appears that inadequate prior knowledge of area and perimeter is the root cause of these misconceptions. This article provides suggestions on how to deal with the concepts of area and perimeter.

\section{Introduction}

Research in the field of mathematics education, locally and internationally, often reveals poor understanding of the concepts of area and perimeter (Gough, 2004; Helen \& Monicca, 2005; Tirosh \& Stavy, 1999). It was found that the concepts of area and perimeter are a continual source of confusion for learners. Van de Walle, Karp and Bay-Williams (2014) suggest that it is perhaps because both area and perimeter involve measurements, or because students are taught formulae for both concepts at about the same time, that they tend to get the formulae confused. The confusion between these two concepts results in learners developing misconceptions.

This article is based on the study by Machaba (2005), which posed the following questions:

- How do Grade 10 learners describe the concepts of area and perimeter?

- How do Grade 10 learners solve problems involving area and perimeter and the relationship between them?

- What misconceptions are evident?

- What might be at the root of these misconceptions?

In this article, I argue that learners lack conceptual understanding of the concept of area and they do not know what a perimeter is. It further appears that inadequate prior knowledge of area and perimeter is the root cause of these misconceptions.

Firstly, the location of this study in the curriculum will be discussed. I will then explain and describe the concepts of area and perimeter and the thought processes around area and perimeter, drawing from a variety of publications. After describing the theoretical framework of the study, the methodology used and the analysis of the data, the conclusion of the study once again focuses on the research questions and the answers yielded by an analysis of the data. Finally, I will make practical suggestions on how educators and textbook writers or curriculum designers can improve learners' ability to deal with the concepts of area and perimeter.

\section{Location in the curriculum}

The National Curriculum Statement for Mathematics, Grade 7-9, determines that learners should be able to describe and represent the characteristics of and relationships between 2-D figures and 3 -D objects in a variety of orientations and positions (Department of Education, 2003). This means that learners should be able to apply their knowledge of area and perimeter appropriately in various situations.

The Gauteng Institute for Curriculum Development (1999, p. 46) in their progress map argue that learners should develop an understanding of the relationship between area and perimeter and use appropriate methods to solve problems involving area and perimeter. For example, learners 
should notice that all rectangles with the same perimeter will not necessarily have the same area and, where necessary, learners should be able to develop general formulae to calculate the area and perimeter. This means that learners should develop a conceptual understanding of area and perimeter through measuring areas and perimeters in a realworld context. They should work concretely (fitting, cutting, folding, matching and counting) to develop an understanding of the concept of area and should simultaneously develop the appropriate language to explain area. They should compare different regular and irregular figures and explain and justify which would be more suitable for measuring area (for example, it is easier to measure the area of a square than that of a circle, because no open spaces are left unmeasured when measuring the area of a square). They should also devise methods to measure the areas of regular and irregular figures (Gauteng Institute for Curriculum Development, 1999, p. 45).

\section{What are area and perimeter?}

Dickson (1989, p. 79) defines area as 'the amount of surface of a region', and perimeter as 'the distance around the region'. She argues that these definitions are not adequately covered in the lower grades, when learners merely learn to define area as the product of length and breadth $(A=l \times b)$, which is completely divorced from the idea of covering surface. Nunes, Light, Mason and Allerton (1994) concur that children's success in understanding area is not independent of the resources they are given to represent area during problem-solving. Learners need objects or resources like bricks and cuttings which they can fit, fold, match and count (Gauteng Institute for Curriculum Development, 1999), so that they can work concretely to develop a conceptual understanding of area and perimeter. This implies that for learners to understand the concept of area and perimeter, the formula length $\times$ breadth does not suffice.

\section{Relationship between area and perimeter: Mysterious connection}

The mathematics education literature reports that many learners and even adults adhere to the view that figures with the same perimeter must have the same area (e.g. Outhred \& Mitchelmore 1996; Tirosh \& Stavy, 1999; Tsamir \& Mandel, 2000; Kidman, 2001; Helen \& Monicca, 2005; Van de Walle et al. 2014). These studies interpreted learners' responses as resulting from a misunderstanding of the concepts of area and perimeter, that is, figures with the same perimeter must have the same area and vice versa. Furthermore, Tirosh and Stavy (1999) found that for a significant percentage of learners a predictable relationship between area and perimeter is that when the area of a figure decreases or increases, the perimeter will also decrease or increase. Learners may not realise that it is possible to have many rectangles with the same area, but different perimeters. If the perimeter is the same in a set of rectangles, then the area of those rectangles does not have to be the same. For example, rectangles with the same area can have many different perimeters. For example, a $3 \times 4$ and a $2 \times 6$ rectangle have the area of 12 square units, but their perimeters are 14 units and 16 units respectively. Rectangles with the same perimeter can have many different areas. For example, a $3 \times 4$ and a $2 \times 5$ rectangle both have a perimeter of 14 units, but their areas are 12 square units and 10 square units respectively.

On the other hand, learners can also establish a relationship between area and perimeter that rectangles with the same area have dimensions that are factors of the fixed area. When the difference between the dimensions of a rectangle with a fixed area is the smallest, you will have the smallest perimeter. When the difference between the dimensions of a rectangle with a fixed area is the largest, you will have the largest perimeter. Given a fixed perimeter, the rectangle with the largest area will be the one with the dimensions that are closest together (a square). Given a fixed perimeter, the rectangle with the smallest area will be the one with the dimensions farthest apart.

The literature, as stated above, indicates that there are many misconceptions for learners and adults about the complex relationship between area and perimeter. Learners need to have experiences in which they are manipulating the spaces that they are measuring, to construct deep understanding. Because of this, it is important to use a variety of manipulatives to develop the concepts. If these are not used, learners would view the relationship between area and perimeter as the result of the application of the intuitive rule 'Same A - Same B' (Same perimeter - Same area; Same area - Same perimeter). This kind of mysterious connection between perimeter and area is further discussed below.

\section{Misconceptions about area and perimeter}

Olivier (1989, p. 12) defines misconceptions as 'errors or wrong answers that are systematic in that they are applied regularly in the same circumstances'. He says they are symptoms of underlying conceptual structures that are causes of error. Smith, diSessa and Roschelle (1993, p. 1) argue that misconceptions are flawed ideas that are strongly held by a student and which interfere with learning. Clement, in Confrey (1990, p. 18), defines misconception as 'conceptual stumbling blocks, inconsistent semi-autonomous schemes, and cognitive processes responsible for errors in problem solving'. These definitions imply that misconceptions are a part of learning and that they are inevitable, but, if noticed, they can be dealt with appropriately. When learners construct knowledge, reconstructing and reorganising their prior knowledge and aligning it with their new knowledge, misconceptions are likely to arise. The point here is that misconceptions are not mistakes that can easily be corrected by telling the learners that they are wrong. Learners need experiences that will enable them to reorganise their thinking.

Olivier (1989, p. 12) states that 'if we want to account for pupils' misconceptions, we must look at pupils' current schemas and how they interact with each other, with instruction and with experience'. This means that 
misconceptions are a function of how learners construct knowledge. This is also supported by Smith et al. (1993), who argue that misconceptions arise from prior learning, either in the classroom (especially for mathematics) or from learners' interactions with the physical and social world.

Olivier (1989) believes that the source of misconceptions is mostly an overgeneralisation of previous knowledge (knowledge that was correct in an earlier domain) to an extended domain (where it is not valid). This means that learners who have been taught the formulae for the areas of a square and a rectangle in their early stages of learning, overgeneralise these formulae, extending them to other figures such as triangles and irregular figures. In other words, they use the formula length times breadth for all figures. Dickson (1989) asserts that most children responded to the word 'area' by saying 'length times breadth', irrespective of the figure being considered.

Another common misconception has been researched by Tsamir and Mandel (2000). They argue that if learners are presented with a square where one side is lengthened and the other shortened by the same amount, these learners claim that both the perimeter and the area of the created rectangle are equal to the perimeter and area of the original square. They claim that learners are using a rule called 'Same A - Same B', a rule based on their intuition. Learners' justifications of their answers were based on the intuition that if the same number was transferred from one place to another, there would be no change in the perimeter or the area of the figure formed. This type of reasoning has been explained by Piaget's theory about the use of compensation to attain conservation. Kidman (2001) and Zacharos (2006) concur that the learners intuitively had a perception of area, where doubling the length of the sides of a rectangular region can be seen as doubling the area. These support research findings by Outhred and Mitchelmore (1996), who argue that learners believe that when the sides of a square are doubled, so is its area. I was interested to see if the result of the current research study would produce the same misconception of 'Same A - Same B' as has been explained above.

Nunes et al. (1994, p. 256) indicate that the concept of area is 'prone to misconceptions, is difficult to teach, and that misconceptions are retained even in the upper middle school age range'. They cite the most common misconception of the relationship between the area and perimeter, which is that the area delimited by the perimeter remains the same, even though the figure and delimited surface have changed. This was evident when limiting an area with a string fixed at the corner and gradually changing the surface by moving the tacks that held the other three corners. They said children tend to think that the area remains constant, despite the visible changes in the surface. They argue that another cause of these misconceptions is that learners are taught or learn a procedure or formula for the area of the rectangle, rather than forming a solid understanding of the relationship between the side lengths and the area of the figure.
In my study I was interested to see if learners in South Africa do the same as reported by Dickson (1989) and Tsamir and Mandel (2000). Do learners in South Africa overgeneralise? Do they apply the 'Same A - Same B' intuitive rule? And if so, what reasons do they give for their conceptions?

\section{Theoretical framework}

This study is informed by Piaget's theory of constructivism, which is about learners assimilating new learning into their existing schema. Constructivism holds that learning occurs efficiently and effectively when new knowledge is linked to existing or prior knowledge (Hatano, 1996). Kramer (1996, p. 6) states that one of the important contributions of Piaget's ideas is the notion that 'learners build or construct new knowledge or skills based on what they know or can do'. This means that learners cannot learn mathematics effectively in isolation from what they are already familiar with. This theory is supported by Mogari (1998), when he says learners do not enter classrooms with blank minds. Instead, they bring with them ideas, conceptions and experiences about mathematical principles, practices and concepts. The theory of constructivism also emphasises the fact that the construction of knowledge is dependent not only on what the child already knows, but also on what they have to know.

Skemp (1976, p. 20) describes this kind of understanding as 'instrumental understanding' and contrasts it with 'relational understanding'. Instrumental understanding is manifested when learners know rules and formulae and have the ability to use them without reason, not knowing where those rules and formulae come from. For example, many learners know that the formula to calculate the area of a rectangle is 'length multiplied by breadth', but they do not know why this is so. He argues that learners should develop a relational understanding of area and perimeter. In other words, learners should know both 'what' to do and 'why' when dealing with problems that involve area and perimeter (Skemp, 1976, p. 20). This also implies that learners should be able to associate or relate the concepts of area and perimeter with other mathematical concepts and their everyday life experiences. For example, Skemp mentions in his research that he asked his learners the question: 'What is the area of a field $20 \mathrm{~cm}$ by 15 yards?' The reply was: '300 square centimetres'. When asked why not 300 yards, his learners replied that 'area is always measured in square centimetres' (p. 23).

The integrated networks of connections between ideas referred to as cognitive schemas are the product of constructing knowledge and the tools with which additional new knowledge can be constructed (Skemp, 1976). Thus, Van de Walle (2007) defines understanding as the quality and quantity of connections that an idea has with existing ideas. Understanding depends on the existence of appropriate ideas and the creation of new connections.

Understanding at this rich and strongly interconnected end of the continuum can be referred to as 'relational understanding', while that at the other end of the continuum, 
where the ideas are completely isolated, can be referred to as 'instrumental understanding' (Skemp, 1976; Van de Walle et al. 2014). Knowledge learned by rote, where ideas are nearly always isolated and disconnected, is almost always understood instrumentally. When learners come by knowledge through self-discovery, it has more meaning because it facilitates the process of building cognitive structures (constructing a network of connected ideas) and because the recall of information (concepts and procedures) is far easier than when knowledge is given (Van de Walle et al. 2014). Relational understanding suggests that when a learner solves a mathematical problem, they arrive at a concept which is in fact produced from a schema (a network of connected ideas). This process produces the kind of learner who is independent, able to think, able to express ideas and to solve problems, representing a shift to a learnercenteredness, that is, learners as knowledge developers and users, rather than storage systems and performers.

\section{Methodology}

The research methodology used in this study was qualitative and was organised around a written test administered to 30 learners as well as a clinical interview carried out with a sample of six learners. The interviews were conducted after all the learners had written the test of six questions (Figure 1), which was based on previous studies such as those discussed above. In the interview I probed my participants to explain their interpretations, experiences and insights with regard to each of their responses to the test items and their reasoning when it comes to the concepts of area and perimeter.

Grade 10 learners were chosen from a secondary school in Soshanguve. The reason why I chose this school was because I was not teaching in this school. This assisted to minimise researcher bias that might emerge from familiarity with the learners and with the school concerned. Below is the written test that was given to learners to write on the concept of area and perimeter.

\section{Rationale for the choice of questions}

\section{Question 1}

This question tests learners' conceptual understanding, without using formulae, and their ability to express these ideas or concepts in words.

\section{Question 2}

This question was also aimed at testing learners' understanding of the concepts of area and perimeter, without being given numbers or measurements. It tests whether learners are able to count square units to determine the area of a figure. It also tests whether learners know that calculating the area of a rectangle by multiplying the number of square centimetres in a row by the number of rows is the same as multiplying the number of square centimetres in the length by the number of centimetres in the breadth.

\section{Question 3}

This question tests the learners' ability to calculate the perimeter and area of an irregular figure when given measurements.

\section{Question 4}

This question tests learners' understanding of the concept of area and whether they can measure the area of an irregular figure.

\section{Question 5}

This question tests learners' understanding of the relationship between area and perimeter and whether they apply the intuitive 'Same A-Same B' rule, finding that when increasing the length of two opposite sides of a square by a given factor and reducing the length of the other two remaining sides by the same factor, the perimeter and the area will remain the same.

\section{Question 6}

This question tests learners' understanding of the relationship between area and perimeter and their application of the intuitive 'Same A-Same B' rule, finding that when increasing or multiplying the length of two opposite sides of a square by a given factor and reducing or dividing the length of the other two remaining sides by the same factor, the perimeter and the area will remain the same.

To reiterate, the purpose of the study was to investigate the insights and misconceptions that some Grade 10 learners in one school in Soshanguve have with regard to the concepts of area and perimeter. A written test was administered to 30 learners in a classroom and an interview was conducted with a selected six of these learners. However, for this article I report on the results of only three of the learners with whom the interviews were conducted, because only from them had I obtained saturated data, so I was forced to omit the data obtained from the other three learners. The results of the interviews and the written test will be reported simultaneously.

\section{Ethical considerations}

Permission to conduct the research was granted by the Gauteng Department of Education, the district and the school where this research was conducted. As this study was not conducted at my school, I wrote a letter to the principal of the school, describing the required grade (Grade 10) and the purpose and the rationale of the study. Grade 10 learners were informed of the study so that they could decide whether or not to participate in the study.

Learners who agreed to participate in the study were guaranteed anonymity and confidentiality. At both school and individual levels, participants' anonymity and confidentiality were maintained by use of pseudonyms (e.g. L1, L2 and L3). Learners were informed that their real names would not be used in the study and whatever they 


\section{Question 1}

Define the following concepts in your own words, without using a formula.

(a) Area

(b) Perimeter

\section{Question 2}

What is the area and perimeter of each of the diagrams below?

(a)

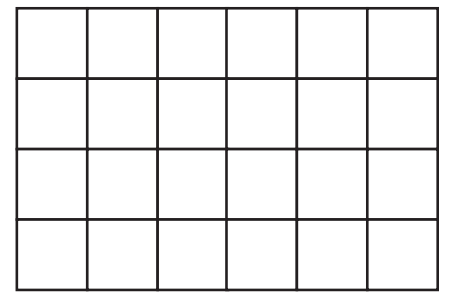

(b)

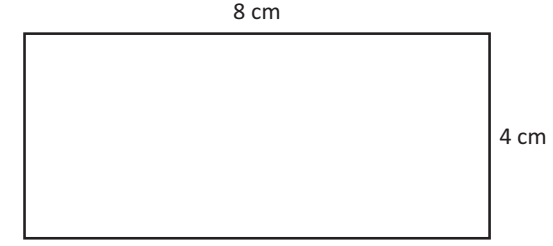

\section{Question 3}

What is the area and perimeter of the figure below? Show how you calculated your answer.

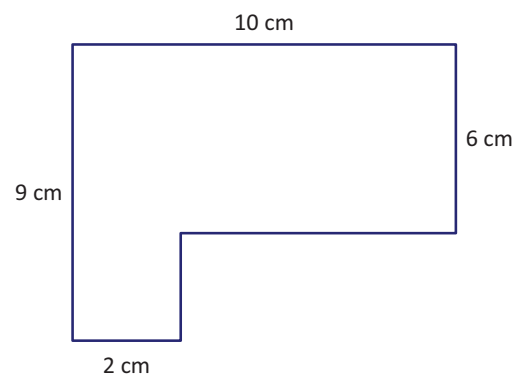

\section{Question 4}

Does this leaf have an area? If yes, how will you find out what it is? Work out its area.

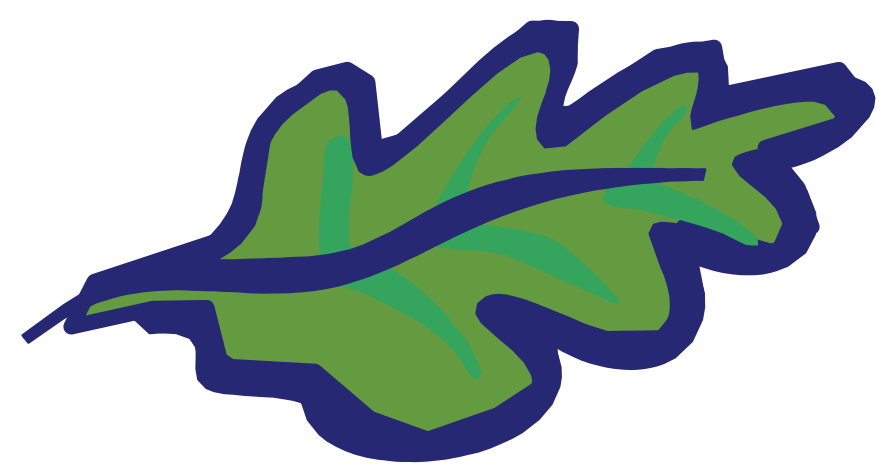

Source: Adapted from Dickson (1989), Outhred \& Michelmore (1996) and Tsamir \& Mandel (2000) FIGURE 1: The written test on area and perimeter. 


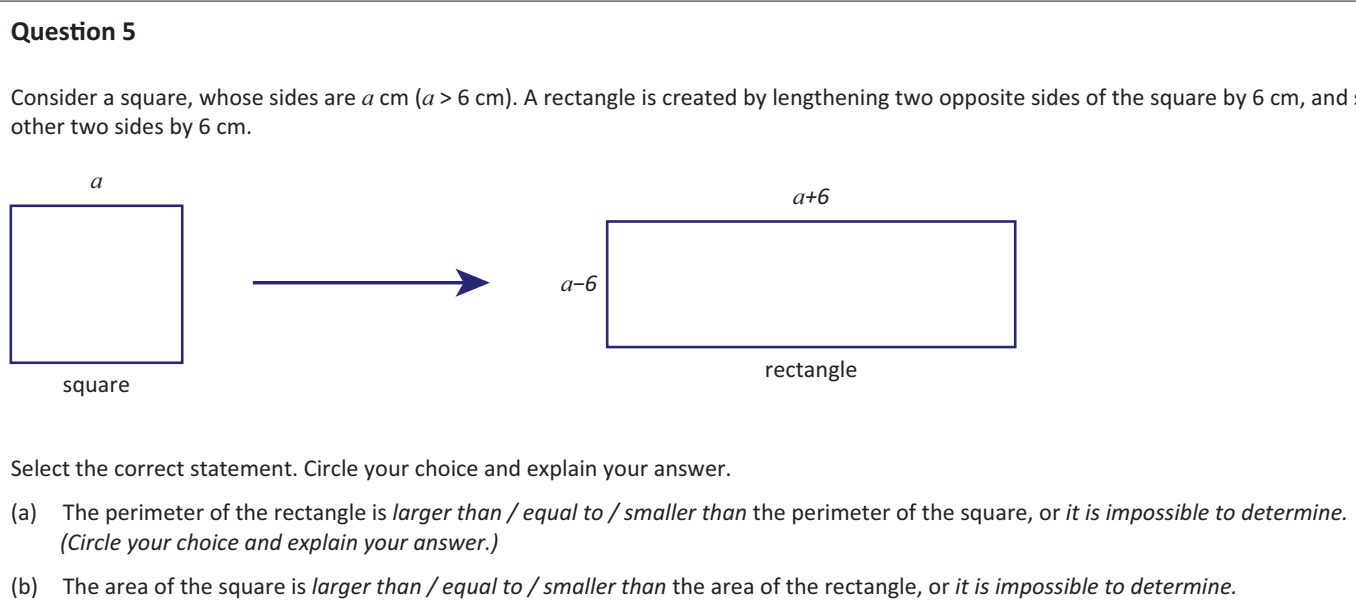

(b) The area of the square is larger than / equal to / smaller than the area of the rectangle, or it is impossible to determine.

\section{Question 6}

Consider a square. A rectangle is created by multiplying the length of two opposite sides of the square by 6 , and reducing the length of the other two sides by the same factor, as described in the drawing.

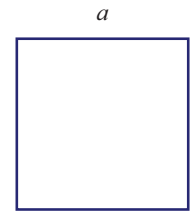

square

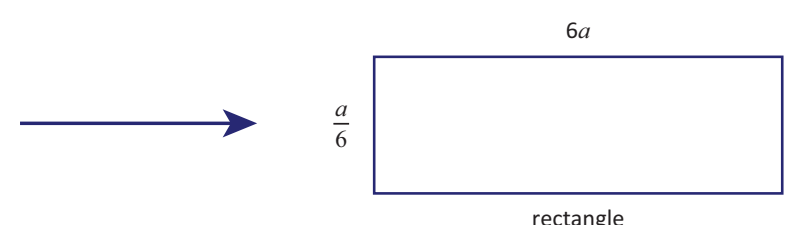

Select the correct statement. Circle your choice and explain your answer.

(a) The perimeter of the rectangle is larger than / equal to / smaller than the perimeter of the square, or it is impossible to determine.

(b) The area of the rectangle is larger than / equal to / smaller than the area of the square, or it is impossible to determine.

Source: Adapted from Dickson (1989), Outhred \& Michelmore (1996) and Tsamir \& Mandel (2000)

FIGURE 1 (Continues...): The written test on area and perimeter.

said would be kept confidential. I developed a rapport with them so that they would not perceive me as an evaluator or judge, that is, as somebody who wanted to detect their learning flaws or faults that could be used to determine their promotion. Rather, I intended to be perceived as one who was interested in how they think and reason mathematically. Participants were informed that they would be provided with the report of the study.

\section{Reliability and trustworthiness}

Data were collected by me using both the instrument (test) and interviews. To ensure reliability of the instrument I initially collected pilot data and then tested an instrument to see if it would be interpreted in the same way. Since some of the questions had not yet been used in any research before, I thought it would be imperative to find out whether the test items were appropriate and tested my critical questions through piloting. I involved five Grade 10 learners in piloting. I gave test items to each and they spent 45 minutes on average answering the questions. I marked their test and chose two learners for an interview. The selection of the two was based on how they had answered the test items. I selected one whose performance was good in the test and one who performed poorly.

Furthermore, I presented the test at conferences and postgraduate meetings, where it underwent rigorous peer reviewing before taking its final form. Because I interviewed few learners, one cannot generalise the findings beyond the studied cases. This is the nature of case studies. However, consistent with the objective of the study, the findings could provide principles for dealing with learners' misconceptions.

Table 1 shows the learners' performance in each of the questions and the numbers and percentages of correct, partially correct and incorrect answers given by all 30 learners who wrote the test.

\section{Findings}

The findings as summarised in Table 1 reflect poor performance in almost all questions, with the exception of Question 2b, which 63\% of learners answered correctly. It would seem that most of the learners had not yet come 
TABLE 1: Summary of findings $(N=30)$.

\begin{tabular}{cccc}
\hline Question & Correct (\%) & Partially correct (\%) & Incorrect (\%) \\
\hline $1 a$ & 10 & 23 & 67 \\
\hline b & - & 10 & 90 \\
\hline a & - & 10 & 90 \\
\hline $2 b$ & 63 & - & 37 \\
\hline 3 & - & 17 & 83 \\
\hline 4 & - & 27 & 73 \\
\hline $5 a$ & - & 17 & 83 \\
\hline $5 b$ & - & 23 & 77 \\
\hline $6 a$ & - & 47 & 53 \\
\hline $6 b$ & - & 17 & 83 \\
\hline
\end{tabular}

across the mathematical concept of perimeter. This is evident from the fact that none of the learners could define perimeter.

It was therefore imperative to find out during the interview why learners were unable to define area and perimeter without using the formulae. It is evident from Table 1 that $67 \%$ of the learners answered Question 1a incorrectly, while $90 \%$ failed to answer Question $1 \mathrm{~b}$ correctly. The answers to the rest of the questions were also interesting, with more than $50 \%$ incorrect answers. I hoped to discover the reasons for this during the interviews.

Of course, the table does not show how the learners solved the problems, or how during the interviewing process some were able to obtain the correct solutions. The discussion that follows is an analysis of the responses of the three selected learners to each of the questions in the test and during the interview.

I will refer to the three learners that were interviewed as L1, L2 and L3, without implying through the labelling the order in which they were interviewed. The researcher will be referred to as the 'interviewer' in the transcript.

The major finding was that the learners held the same misconceptions that had been identified by other researchers. This claim is based on both the test responses and the followup interviews.

\section{Area is length multiplied by breadth}

The learners cited the ingrained, formalised method of multiplying length by breadth to get the area. This indicates a lack of conceptual understanding of area as a surface and perimeter as the distance around the edge of the figure. The learners described both the area and the perimeter in terms of a formula. For example, with regard to Question 1a and Question 1b, L1 responded as follows:

L1: It is the answer that you get after multiplying both the length and the breadth.

Interviewer: Why did you define by using the formula, when you had been forbidden to use the formula?
L1:

Mmm. ... I use the formula because there was no other way I can define the area without using the formula.

L1: Perimeter is the sign of showing that it is a cm, $\mathrm{km}$ or $\mathrm{m}$.

Interviewer: What do you mean? Can you say more on that?

L1: I mean like in a ruler [showing me a ruler], these are millimetres and centimetres, these are perimeters.

Similarly, L2 responded as follows:

L2: [Perimeter] is the size of an object.

Interviewer: Have you ever heard about the word perimeter in your life?

L2: No.

\section{Overgeneralisation}

The learners overgeneralised when moving from working with rectangles to working with non-rectangles. They thought that the formula $A=l \times b$ could be applied to nonrectangles. For example, the learners responded as follows to Question 5:

L1: No, the leaf does not have an area because there is no length and breadth.

L3: $\quad$ I do not think the leaf has an area, because the leaf is not a rectangle and does not have length and breadth.

\section{Same A - Same B}

The learners claimed that when the length of two opposite sides of a square were increased by a given number of centimetres and the length of the other two sides were decreased by the same number of centimetres, both the perimeter and the area would remain the same. Similarly so if the length of two sides is multiplied by a certain factor and the other sides are divided by the same factor.

\section{The response to Questions 6 was as follows:}

Interviewer: You said your answer would be 'equal to' in your solution of 6(a) and 6(b). Can you give a reason why you said so?

L1: Sir, I think if you lengthened these two sides of the square, nee! ... by 6 nee!! ... mmm ... and shortened the other two sides by 6 again [talking and demonstrating with her hands and fingers] is like you did nothing, is like you add 6 subtract 6 is zero, so that is why I say the answer is equal.

Interviewer: Which means, what you are saying is the perimeter of the rectangle will be equal to the perimeter of square?

L1: $\quad$ Yes, Sir. 
Interviewer: What about the area?

L1: The area of the square will also be equal to the area of rectangle.

Interviewer: Why are you saying so?

L1: $\quad$ Because, Sir, you add 6 and subtract 6 .

It is clear that $\mathrm{L} 1$ uses the intuitive 'Same A - Same B' rule when solving the problem. L2 did likewise:

L2:

No, I think the perimeters of the two diagrams are equal, Sir.

L2:

Because the two opposite sides of the square are increased by $6 \mathrm{~cm}$ and the other two have been also decreased by $6 \mathrm{~cm}$.

Interviewer: What about the area of the two diagrams?

L2:

I think, are also equal because of the $6 \mathrm{~cm}$, which was added and subtracted.

The application of the intuitive 'Same A - Same B' rule confirms findings by (Tsamir \& Mandel, 2000). In their findings, they reported that in the same mathematical problem learners correctly claimed that the perimeters of the square and the rectangle are equal when adding and subtracting $6 \mathrm{~cm}$ to opposite sides of the square. This type of reasoning has been explained by Piaget's theory about the use of compensation to attain conservation. Tirosh and Stavy (1999) also viewed these responses as an instance of the intuitive 'Same A - Same B' rule. This rule is an instance of overgeneralising and arriving at erroneous conclusions such as that if the perimeter of the original square is equal to the perimeter of the created rectangle, the areas of these figures must be equal too.

\section{Discussions and conclusion}

In this section, I shall return to my research questions and answer them on the basis of the analysis of my data. I will treat each question as a subheading of this section when stating my findings. I shall state explicitly what I have found. Lastly, I will discuss the implications of my findings and reflect on them.

The critical questions that guided this study were: How do Grade 10 learners describe the concepts of area and perimeter? How do Grade 10 learners solve problems involving area and perimeter and the relationship between them? What misconceptions are evident when learners are solving these problems? What might be the cause of these misconceptions?

\section{How do learners describe the concept of area?}

Learners had problems defining the concept of area without using the formula $A=l \times b$. Most learners were unable to define area as the amount of a surface of a region, with the exception of L2 and L3, who used the everyday notion of area as being a 'place' or a 'space'. In terms of Skemp (1976), these learners do not have relational understanding (knowing what to do and why), but an instrumental understanding (doing something without understanding) of the concept of area. They were unable to build on their existing knowledge (schema) of the area as a surface which they should have possessed to create a new knowledge of the formula of an area. This means that learners do not have a conceptual understanding of area. It appears that they do not know where the formula $A=l \times b$ comes from or why $A=l \times b$. Kilpatrick, Swafford and Findell (2001, p. 119) say that a significant indicator of conceptual understanding is being able to represent mathematical situations in different ways and knowing how different representations can be useful for different purposes. In this study, with the exception of L2 and L3 who used the everyday notion of area as a 'place' or a 'space', learners could not, apart from the formula $A=l \times b$, give any different representations or use methods like the square centimetre grid. It appeared to me that these learners do not know that the formula $A=l \times b$ generalises an arithmetic pattern (Usiskin, 1998) and is derived from somewhere. This was evident to me when none of the learners mentioned the word grid or something similar. Dickson (1989) also found a lack of conceptual understanding of area in her research, when she indicated that some of her learners defined area as $A=l \times b$, yet regarded it as completely divorced from the idea of covering surface.

\section{How do learners describe the concept of perimeter?}

I found that learners do not know what the concept 'perimeter' entails. None of the learners could correctly define perimeter. One of the learners defined perimeter as units, for example $\mathrm{km}, \mathrm{m}$, cm, while others defined perimeter as 'the length and breadth'. Dickson (1989) defines perimeter as the distance encompassing a region. None of the learners defined perimeter in this way. I can only assume that the lack of knowledge about perimeter is because it is not an everyday notion as area is.

\section{How do learners solve problems involving area and perimeter and the relationship between them?}

In this study learners were able to calculate area when given measurements, but were unable to determine the area when measurements were not given on the figure. They did not know that the area could be determined through counting square centimetres. Their failure to make a connection between the figure with square centimetres and the one with measurements leads us to conclude that they also lack a conceptual understanding of area. The lack of the integrated network of connections between ideas (cognitive schema) was the product of being unable to construct new knowledge based on existing knowledge. Learners who have difficulty translating a concept from one representation to another have difficulty solving problems and understanding computation (Van de Walle et al. 2014). This is where the idea of Smith et al. (1993) comes into play, namely that making connections between multiple representations helps to 
develop meaning. All three learners responded by saying that an irregular figure (such as that of a leaf) does not have an area, because it does not have length and breadth. This implies that these learners only know the procedure or formula for calculating area fluently, accurately and efficiently when given numbers to substitute, which Skemp (1976) refers to as instrumental understanding. Kilpatrick et al. (2001) maintain that learning procedures without connections to understanding, meaning or concepts is merely memorisation and at the lowest level of cognitive demand.

Learners were unable to calculate perimeter, which shows that they do not have an understanding about the concept of perimeter. In their research report, Kilpatrick et al. (2001) say that when learners have acquired conceptual understanding in an area of mathematics, they see the connections among concepts and procedure and (that) some facts are consequences of others. This report confirms that learners lack conceptual understanding (relational understanding) of area and perimeter and the connections between them.

\section{What misconceptions are evident when learners are solving problems related to area and perimeter?}

The first misconception that these learners displayed was overgeneralisation. They thought that the formula $A=l \times b$, which is used for rectangles, could be used for non-rectangles as well. This was evident when L1 multiplied $10 \mathrm{~cm}$ by $9 \mathrm{~cm}$ to get an area in Question 4. Dickson (1989) found that most children responded to the word 'area' by saying 'length times breadth', irrespective of the figures being considered (rectangles or non-rectangles). It was interesting to see that one learner showed a working knowledge of subdividing the L-shape in Question 4 into rectangles to enable him to apply the 'length times breadth' formalisation.

The second misconception that was found was the application of the intuitive 'Same A - Same B' rule. Learners claimed that when increasing the lengths or adding a certain figure to the lengths of two opposite sides of a square and reducing the lengths or subtracting the same figure from the lengths of the other two remaining sides, the perimeter and the area would remain the same. This finding resonates with the findings of Tsamir and Mandel (2000). Learners also claimed that when increasing or multiplying the size of two opposite sides of a square by a given factor and reducing or dividing the size of the other two remaining sides by the same factor, the perimeter and the area would remain the same. All the learners (L1, L2 and L3) therefore correctly claimed that the perimeters of the square and the rectangle would be equal when adding and subtracting $6 \mathrm{~cm}$ to opposite sides of the square (Question 5). They also correctly claimed that the area of the rectangle remained the same when multiplying and dividing opposite sides of the square by equal factors. However, in each instance they extended their claims to the other concept as well (to the area in the addition and subtraction of a certain length of the sides and to the perimeter in the multiplication and division of the lengths of the sides).

Tsamir and Mandel (2000) confirm that correct answers found with an intuitive rule therefore do not necessarily reflect students' understanding of the concepts. All the learners (L1, L2 and L3) wrongly assumed that when two opposite sides of a square are lengthened by $6 \mathrm{~cm}$ and the other two sides are shortened by the same number $(6 \mathrm{~cm})$, then the area of the given square would be equal to that of the resulting rectangle. They also wrongly assumed that when two opposite sides of a square are multiplied by $6 \mathrm{~cm}$ and the other two sides are divided by $6 \mathrm{~cm}$, the given square and the created rectangle would have the same perimeters. The justifications of their claims were in line with the application of the intuitive 'Same A - Same B' rule.

Learners also wrongly concluded that if the perimeter of the original square in Question 5a is equal to the perimeter of the created rectangle, the perimeter of the original square in Question 6a would also be equal to that of created rectangle and that if the area of the original square in Question $6 \mathrm{~b}$ is equal to the created rectangle, the area of the original square in Question 5b would be equal to that of the created rectangle. This erroneous conclusion is another form of overgeneralisation which indicates a lack of knowledge of the two concepts: perimeter and area. Tirosh and Starvy (1999) suggest two ways in which the intuitive rule 'Same A - Same B' are formed; they indicate that: (1) it may be one of a small set of universal, innate primitives and (2) it is an overgeneralisation from successful experiences. Often, both in everyday life and in school situations, the rule 'Same A - Same B' is in fact applicable (e.g. 'same heights of juice in two identical cups - same amount to drink', 'same number of candies - same price'). It is reasonable to assume that children generalise such experiences into a universal maxim: 'Same A - Same B'.

\section{What might be causing these misconceptions?}

It was evident from their incorrect definitions of area and perimeter that all three of the interviewed learners lacked prior knowledge of area and perimeter and that they had no conceptual understanding of perimeter as a distance. Furthermore, none of them mentioned the square centimetre grid in their discussion with the interviewer. Learners could not add new knowledge to the existing knowledge by making sense of what is already inside their heads. They could not organise, structure and restructure their experience in the light of available schemes of thought (Van de Walle et al. 2014). Dickson (1989, p. 79) says that the confusion between area (the amount of surface) and perimeter (the distance round a region) is nearly always due to inadequate preparation in the early stages', when the learners are given the formulae $A=l \times b$ and $P=2(l+b)$ without adequate explanation of the concepts. This is also confirmed by Olivier (1989) and Smith et al. (1993), who argue that prior knowledge or existing knowledge may contribute to the development of misconceptions in the cognitive structure of the learner. 
The misconceptions created by prior learning were evident when learners applied the formula $A=l \times b$ to non-rectangles. It was further evidenced that misconceptions resulted from structures $(A=l \times b)$ that apply appropriate in one domain (a rectangle) being overgeneralised to another domain (non-rectangles).

\section{Summary of results}

In the light of the above findings I can say that in dealing with the concepts of area and perimeter, learners have the following problems:

- They lack conceptual understanding of area as a surface. This became evident when they described area as length multiplied by breadth.

- They overgeneralise, in other words, they assume that the formula $A=l \times b$, as applied to rectangles, can also be applied to non-rectangles.

- They use the intuitive 'Same A - Same B' rule when dealing with area and perimeter and therefore obtain only partially correct (false positive) results. They believe that when the size of two opposite sides of a square are increased by a given factor and then the size of the other two remaining sides is decreased by the same factor, the perimeter and the area would remain the same.

\section{Implications}

This study, like other similar studies (e.g. Dickson, 1989; Tirosh \& Stavy, 1999), suggests how teachers, textbook writers and curriculum designers could improve learners' understanding of the concepts of area and perimeter. Teachers should drastically change their approach in teaching these concepts, by shifting the emphasis away from teaching the formulae for area and perimeter to making use of activities that would develop learners' conceptual understanding of area and perimeter. They should ensure that learners develop a conceptual understanding of area and perimeter by using square centimetre grids and by letting the learners do fitting, cutting, folding and counting activities, instead of teaching them formulae like $A=l \times b$ and $P=2(l+b)$, procedures, rules and principles, without explaining where they come from and why they are that way.

Teachers should distinguish between the concepts of area and perimeter, yet emphasise the relationship between them, so that learners will not see them as isolated concepts. In their progress map, the Gauteng Institute for Curriculum Development (1999) indicate that learners should develop an understanding of the relationship between area and perimeter and use efficient methods appropriately to calculate and solve problems that involve area and perimeter.

If teachers and textbook authors could, in the lower grades, emphasise the fact that the area is the size of a surface and the perimeter is the size of the edge of a figure, many misconceptions could be avoided. The extent of such misconceptions was evident when L2 and L3 responded in Question 5 that a leaf does not have an area, because there is no length and breadth.

Teachers should also be aware of the role that the intuitive rule plays in the concepts that learners form. In other words, when designing problems, teachers should consider whether they might elicit the use of an intuitive rule or counter it. This also implies that teachers should not be satisfied with the correct answers alone, but probe further to be certain that the learners are not just applying the intuitive 'Same A - Same B' rule (Olivier, 1989; Tsamir \& Mandel 2000).

\section{Acknowledgements Competing interests}

The author declares that he does not have financial or personal relationship(s) that may have inappropriately influenced him in writing this article.

\section{References}

Confrey, J. (1990). A review of research on student conceptions in mathematics, science and programming. In C. Cazden (Ed.), Review of research (pp. 3-56). Washington, DC: American Educational Research Association. http://dx.doi. org/10.2307/1167350

Department of Education. (2003). National curriculum statement Grades 7-9 (General), Mathematics. Pretoria: Department of Education.

Dickson, L. (1989). Area of a rectangle. In Johnson, D. (Ed.), Children's mathematica frameworks: A study of classroom teaching (pp. 76-88). Berkshire: NFERframework.
Nelson.

Gauteng Institute for Curriculum Development (1999). Mathematical Literacy, Mathematics and Mathematical Sciences draft progress map. Johannesburg: Gauteng Department of Education.

Gough, J. (2004). Fixing misconceptions: Length, area, and volume. Prime numbers, $19(3), 8-14$

Hatano, G. (1996). A conception of knowledge acquisition and its implications for mathematics education. In L. Steffe, P. Nesher, P. Cobb, \& G. Goldin (Eds.), Theories of mathematical learning (pp. 197-217). Hillsdale, NJ: Lawrence Erlbaum.

Helen, L., \& Monicca, K. (2005). Investigating teachers' responses to students misconceptions. In H. Chick, \& L. Vincent (Eds.), Proceedings of the 29th Conference of the International Group of Psychology of Mathematics Education (Vol. 2, pp. 249-256). Melbourne: PME.

Kidman, G. (2001). Testing for additivity in intuitive thinking of area. In J. Bobis, B. Perry, B., \& M. Mitchelmore (Eds.), Proceedings of the 24th Annual Conference of the Mathematics Education Research Group of Australasia (pp. 322-329). Sydney: MERGA. Available from http://www.merga.net.au/publications/counter.php? pub=pub_conf\&id=989

Kilpatrick, J., Swafford, J., \& Findell, B. (2001). Adding it up: Helping children learn mathematics. Washington, DC: National Academy Press.

Kramer, D. (1996). OBE strategies, tools and techniques for implementing Curriculum 2000. Florida Hills: Vivlia.

Machaba, F. (2005). Insights and misconceptions that Grade 10 learners in one school in Soshanguve have with the concepts of area and perimeter. Unpublished BEd Honours project. Faculty of Education, University of the Witwatersrand, Johannesburg, South Africa.

Mogari, D. (1998) Geometrical constructs and pupils' construction of miniature wire cars. Pythagoras, 46, 52-56.

Nunes, T., Light, P., Mason, J., \& Allerton, M. (1994). The role of symbols in structuring reasoning: Studies about the concept area. In J. da Ponte, \& J. Matos (Eds.), Proceedings of the 18th Conference of the International Group for the Psychology of Mathematics Education (Vol. 3, pp. 255-262). Lisbon: PME.

Olivier, A. (1989). Handling pupils' misconceptions. Pythagoras, 21, 10-19.

Outhred, L., \& Mitchelmore, M. (1996). Children's intuitive understanding of area measurement. In L. Puig, \& A. Gutierrez (Eds.), Proceedings of the 20th Conference of the International Group for the Psychology of Mathematics Education (Vol. 4, pp. 91-98). Valencia: PME. 
Skemp, R. (1976). Relational understanding and instrumental understanding Mathematics Teaching, 77, 20-26.

Smith, J.P., diSessa, A.A., \& Roschelle, J. (1993) Misconceptions reconceived: A constructivist analysis of knowledge in transition. Journal of the Learning Sciences, 3(2), 115-163. http://dx.doi.org/10.1207/s15327809jls0302_1

Tirosh, D., \& Stavy, S. (1999). Intuitive rules: A way to explain and predict students reasoning. Educational Studies in Mathematics, 38, 51-61. http://dx.doi. org/10.1023/A:1003436313032

Tsamir, P., \& Mandel, N. (2000). The intuitive rule same A - same B: The case of area and perimeter. In T. Nakahara, \& M. Koyama (Eds.), Proceedings of the 24th and perimeter. In T. Nakahara, \& M. Koyama (Eds.), Proceedings of the 24th
Conference of the International Group for the Psychology of Mathematics Education (Vol. 4, pp. 225-232). Hiroshima: PME.
Usiskin, Z. (1998). Conception of school algebra and uses of variables. In A. Coxford, \& A. Shulte (Eds.), The ideas of Algebra, K-12 (pp. 8-19). Reston, VA, National Council of Mathematics Teachers.

Van de Walle, J. (Ed.). (2007). Elementary and middle school mathematics: Teaching developmentally. Boston, MA: Pearson Education.

Van de Walle, J.A., Karp, K.S., \& Bay-Williams, J.M. (Eds.). (2014). Elementary and middle school mathematics: Teaching developmentally. Boston, MA: Pearson Education.

Zacharos, K. (2006). Prevailing educational practices for area measuring and student failure in measuring areas. Journal of Mathematical Behavior, 25, 224-339. http://dx.doi.org/10.1016/j.jmathb.2006.09.003 